\title{
Polysemy and Metaphor in the Verbs of Perception
}

\author{
Mihaela Georgiana Manasia
}

\begin{abstract}
This paper addresses the idea that has been recently put forward by several studies in the field of cognitive linguistics that perception verbs have a polysemous structure motivated by our experience and understanding of the world. Metaphor is not only characteristic of poetic language, but on the contrary, it can be found everywhere in everyday language and the polysemous character of perception verbs reflected into a wide range of syntactic and constructional alternatives makes them a motivating semantic field to approach in this respect.

KEY WORDS: polysemy, metaphor, perception verbs, prototypical meaning, metaphorical meaning.
\end{abstract}

Dolysemy represents, within semantics, the term used to characterize the situation in which a word has two or more similar meanings. Despite this very simple definition, the concept of polysemy has been subject to controversies and continues to remain a debatable field in the linguistic research.

In 1980, the study of polysemy and metaphor expands within cognitive linguistics especially with Lakoff and Johnson's book Metaphors We Live By. They define polysemy as a systematic relation of meanings. It is perceived as categorization namely related meanings are organised into categories based on family resemblance. 
Recent studies in the field of cognitive semantics have tried to put forward that perception verbs have a polysemous structure, motivated by our experience and understanding of the world. Metaphor represents one of the cognitive instruments structuring this variety of meanings and a part of everyday language that affects the way in which we think, perceive and act.

The authors of Metaphors We Live By criticized the classical theory of metaphor as a comparison, describing similarities that already exist. Metaphor creates similarities when we understand something in terms of something else. They stipulate that the majority of concepts allowing us to apprehend reality are metaphorical. The metaphorical conceptual system derives, according to them, from various concepts emerging from our direct interaction with the environment. Therefore, language in its most everyday usage is full of metaphors.

Metaphor is not only characteristic of poetic language, but on the contrary, it can be found everywhere in everyday language: "Metaphor is for most people a device of the poetic imagination and the rhetorical flourish-a matter of extraordinary rather than ordinary language.... We have found, on the contrary, that metaphor is pervasive in everyday life, not just in language but in thought and language. Our ordinary conceptual system, in terms of which we both think and act, is fundamentally metaphorical in nature." ${ }^{1}$

Nevertheless, this device must not be envisaged as a purely linguistic phenomenon, separated from thought because in fact, it represents one of the elements we use to understand the world: "human thought processes are largely metaphorical... Metaphors as linguistic expressions are possible precisely because there are metaphors in a person's conceptual system." ${ }^{2}$

The traditional view on metaphor as characteristic of language rather than thought is thus replaced by the cognitive perspective envisaging metaphors as cognitive devices. Metaphors represent a matter of cognition and are central to conceptualising the surrounding world. Speakers involuntarily and unconsciously use certain metaphors namely the ones which are deeply rooted in our cognition. These are the so-called conceptual metaphors, a term used 
to describe metaphor as a cognitive structure, the one providing the basis for different linguistic expressions.

Conceptual metaphors help us better conceptualize and comprehend concepts that are difficult to grasp. In fact, they enable human beings to partially understand what cannot be fully understood: feelings, consciousness, etc. Therefore, metaphor is not a problem of language but a way of conceptualizing one domain by reference to another: it allows, among others, for the description of a concept by borrowing terms from other areas when appropriate words do not exist. If one uses a more mathematical language, metaphor can be seen as a system of correspondences between a source domain and a target domain. "In metaphor, the structure of a given domain (called the source domain) is mapped onto a different one (the target domain), which as a result is structured and understood in terms of the first one. ... Normally, source domains are more concrete than target domains. The realm of perception is a rather concrete domain and participates as source domain in several metaphors."3

In linguistics, it has been repeatedly pointed out that metaphor only gives us a partial understanding of the target domain, because it must necessarily focus on some aspects of the source domain while concealing others. Hence, totalizing and abstract concepts such as life, death, time etc. are understood due to a large number of metaphors, each giving rise to a large number of linguistic expressions.

Metaphor consists of transposing an existing relationship into a conceptual domain by applying certain qualities from one over the other. This is not random, being generally due not only to physical experience but also to cultural and social experiences.

Metaphors have been classified in various ways by linguists. According to Lakoff ${ }^{4}$ there are three main types of metaphors: conventional metaphors, image-metaphors and generic-level metaphors. The conventional metaphors combine a conceptual domain to another, often associating several concepts of the source domain with several concepts of the target domain. Instead, image-metaphors, based on perception, are also conceptual but associate one image to another. In this case, the source and target 
domains constitute images, our mental representations regarding a particular concept. It sometimes happens that two very different concepts have common physical characteristics when trying to represent them mentally. Thus, the principle of these metaphors consists of allocating certain concepts or physical properties from other concepts (such as size, shape, color....) For example, when we say that a woman has an hourglass figure, we have a certain image of the wasp: it has a rather thin size. We then transpose this image onto that of a woman in order to state that she has thin waist. In fact, these are actually attributional metaphors because they attribute physical properties to concepts. Finally, the metaphor THE GENERIC IS SEEN AS THE SPECIFIC establishes a relationship between a specific structure and a more generic one. Due to this mechanism, we understand a generic situation in terms of specific, based on our ability to extract the generic from the specific.

The polysemous character reflected into a wide range of syntactic and constructional alternatives makes perception verbs a motivating semantic field to approach. A diversity of papers analysing the polysemous structure of perception verbs namely their semantic extensions has been drawn up by various linguists. What differentiates our research from others is that we envisage to contrastively analyze the non-prototypical meanings of perception verbs in English, Romanian and French.

One of the scholars performing this type of research is Viberg who studied verbs of perception in fifty-three languages belonging to fourteen linguistic families. This represents the first largest cross-linguistic study conducted in the field of semantic change. In the case of English, the first conclusion emerging consists of the strong polysemy within this semantic field: nine verbs share the fifteen possible meanings. Cross-linguistically, this is true, very few languages having fifteen different verbs. He has studied polysemy patterns by limiting his analysis only to passive verbs which are more polysemous than active or copulative verbs. All languages have polysemy patterns whose semantic changes correspond to the following scheme: ${ }^{5}$ 


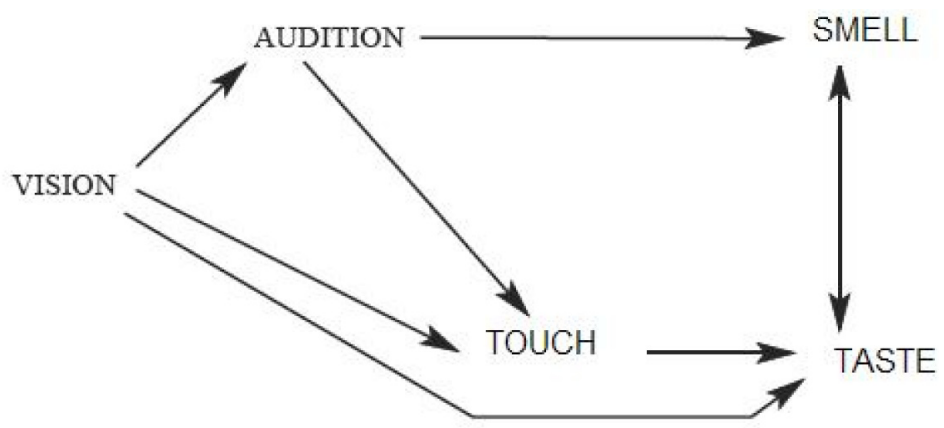

This scheme should be interpreted as follows: if initially, a verb expresses the visual modality, then the allowed extensions are directed towards audition, touch and taste. If the original meaning expresses audition, the possible extensions could be touch and smell. If initially the tactile modality is expressed, taste and smell represent the only possible semantic extensions. Finally, the verbs denoting taste and smell can extend their meanings towards smell respectively taste.

Another well-known linguist, Sweetser ${ }^{6}$ showed interest in the study of the semantic extensions of perception verbs in English. She has advanced the concept of MIND AS BODY metaphor implying the conceptualization of one type of experience namely the mind in terms of another-the body. This metaphor could be considered the equivalent of Lakoff and Johnson's conceptual metaphor. Applying the MIND-AS-BODY conceptual metaphor to English perception verbs, "the metaphorical mappings take place between two domains of experience: the vocabulary of physical perception as the source domain and the vocabulary of the internal self and sensations as the target domain."7

According to Sweetser these correspondences go in a specific direction that is from the domain of bodily experience to that of cognitive and emotional states. This applies to English perception verbs whose metaphorical extensions cover two domains of experience: the source domain represented by the vocabulary of physical perception and the target domain expressed by the vocabulary of internal feelings. 


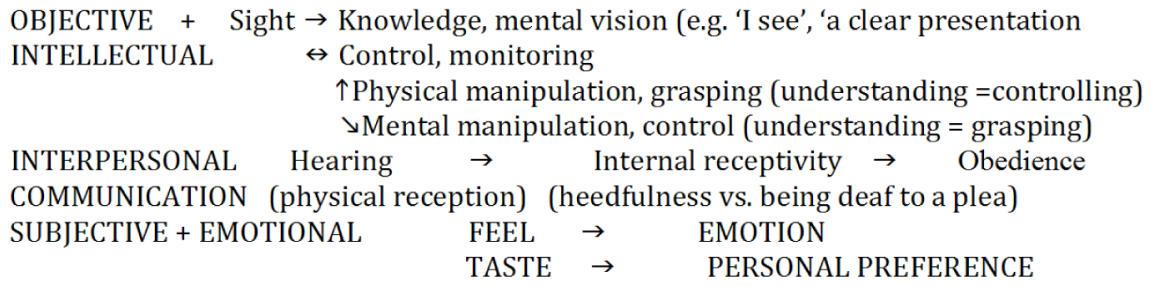

The table above contains ways of semantic extension in English perception verbs identified by Sweetser: ${ }^{8}$

She considers vision to be the main source of collecting objective information given its capacity to select the prominent trait of one stimulus. This is one of the reasons she associates vision with the objective and cerebral part of our mental existence. Nonetheless, there are situations when vision and intellect appear to be subjective but she did not decide to explore this aspect as well. Hearing may also share the semantic extension of vision involving mental activities but they are of a different type because this sense does not allow us to manage the way we receive sounds. Touch can be put in relation with the emotional feeling while taste may allow for the expression of personal likes and dislikes in the mental world. With regard to the olfactory sense, links can be established between a bad smell and a "bad character or dislikeable mental characteristics (e.g. stink) and the detection of such characteristics (e.g. the active verb smell). ${ }^{9}$

The table of English perception metaphors proposed by Sweetser has been enriched with new semantic extensions in the case of the five types of perception. The table on the next page presents the list of the conceptual metaphors in perception verbs proposed by Ibarretxe-Antuñano. ${ }^{10}$

This list is relevant to the polysemous character of perception verbs and raises the issue of the motivated or arbitrary nature of the semantic extensions, of the capacity of verbs such as see (1) or hear (2) to be used with the meaning of understand:

(1) I see what you mean by that.

(2) If I have heard well, they want to say that I have no chance. 


\begin{tabular}{|l|l|}
\hline & \multicolumn{1}{|c|}{ METAPHORS IN THE PERCEPTUAL DOMAIN } \\
\hline VISION & $\begin{array}{l}\text { Understanding is seeing } \\
\text { Foreseeing is seeing } \\
\text { Imagining is seeing } \\
\text { Considering is seeing } \\
\text { Studying / Examining is seeing } \\
\text { Finding out is seeing } \\
\text { Making sure is seeing } \\
\text { Taking care is seeing / looking after } \\
\text { Witnessing is seeing } \\
\text { Suffering is seeing } \\
\text { Obeying is seeing } \\
\text { Refraining is seeing } \\
\text { Being involved is having to see }\end{array}$ \\
\hline HEARING & $\begin{array}{l}\text { Paying attention is hearing } \\
\text { Obeying is hearing } \\
\text { Being told / knowing is hearing } \\
\text { Understanding is hearing } \\
\text { Being trained is being heard }\end{array}$ \\
\hline TOUCH & $\begin{array}{l}\text { Affecting is touching } \\
\text { Dealing with is touching } \\
\text { Considering is touching } \\
\text { Persuading is touching }\end{array}$ \\
\hline SMELL & $\begin{array}{l}\text { Suspecting is smelling } \\
\text { Sensing / guessing is smelling } \\
\text { Investigating is smelling / sniffing around } \\
\text { Showing contempt is sniffing } \\
\text { Corrupting is smelling } \\
\text { Not to get wind of something is not to smell } \\
\text { Prophesying is smelling }\end{array}$ \\
\hline
\end{tabular}

The traditional hypothesis expressing the arbitrariness of the relation between the linguistic forms and concepts they represent is rejected by both Lakoff and Sweester. "Human conceptual categories and the meaning of linguistic structures at any level are not a set of universal abstract features or uninterpreted symbols; they are motivated and grounded more or less directly in experience, in our bodily, physical and socio-cultural experiences. This notion of motivated language is known in Cognitive Linguistics as embodiment."11

Provided that such a concept as embodiment exists, we can put forward the hypothesis that perception metaphors have to be motivated and derived from the way we experience and understand the senses. Human mental faculties (cognition, affection, emotion, etc.) can be metaphorically equated to perceptual processes. The 
metaphor Cognition is Perception is one of the most recurrent in language as our corpus-based analysis will prove. As already mentioned, a connection between perception verbs such as 'see' and 'hear' and the meanings of understand / know can be established:

(3) "Ah, certainly-I see now: you are the favoured possessor of the beneficent fairy,"

I remarked, turning to my neighbour. ${ }^{12}$

(4)'It is Jane Eyre, sir.'

— "Soon to be Jane Rochester," he added: "in four weeks, Janet, not a day more. Do you hear that?"13

The varying degree of reliability and exactness of the information received via senses may also help us to explain certain metaphorical projections of perception verbs. The following set of examples, allowing us to prove this hypothesis, contains identical sentences except for the verb:

(5) a. He saw that there would be problems.

b. He heard that there would be problems.

c. He smelt that there would be problems.

The meaning of the visual verb in (5a) is know, that of heard is to be told while the olfactory verb smell has the meaning of to guess, to suspect. Although these verbs belong to different perception modalities, they are somehow similar in that they all express the idea of knowledge. In spite of the similarities, the meaning conveyed by each sentence is different according to the type of knowledge the verb suggests. Interpretations such as He knew something wasn't right, He was told something wasn't right and He suspected something wasn't right are different as to the degree of reliability and accuracy between the information the perceiver collects and the real object of perception.

In (5a), it is the perceiver himself who has realized that something was wrong after processing in his or her own manner some clues s/he saw. Example (5b) expresses the idea of less reliable information because what somebody else tells us is not as accurate as when we see it with our own eyes. In (5c), the verb of olfactory perception renders the idea of a type of knowledge even less accurate than the hearing verb because the perceiver does not have enough information to base his assumption on. 
In conclusion, these senses allow us to formulate hypotheses regarding the nature and characteristics of the objects we perceive corresponding more or less accurately to the nature of the real object. The information provided by visual perception, and consequently, the hypothesis formulated on the basis of that information is normally more accurate than that gathered by the sense of hearing or smell. Consequently, the use of metaphorical expressions containing verbs such as see, hear, or smell allow us to map that experience from the domain of physical perception onto the more abstract domain of knowledge.

NOTES

${ }^{1}$ George, Lakoff and Mark Johnson, Metaphors We Live By. Chicago (University of Chicago Press, 1980), 3.

${ }^{2}$ Ibid., 6.

3 Rojo, Ana, and Javier Valenzuela. "Frame Semantics and Lexical Translation: the RISK frame and its translation." Babel Volume 44, No 2. (1998).

${ }^{4}$ Lakoff, George. Women, Fire and Dangerous Things. What Categories Reveal about the Mind. (Chicago and London: Chicago University Press, 1987), 31-50.

${ }^{5}$ Äke Viberg,. "The verbs of perception: a typological study" in Explanations for Language Universals ed. B. Comrie and O. Dahl (Berlin: Mouton de Gruyter, 1984), 23.

${ }^{6}$ Sweetser, Eve. From etymology to pragmatics. Metaphorical and cultural aspects of semantic structure, (Cambridge: Cambridge University Press, 1990).

${ }^{7}$ Neagu, Mariana. Cognitive Linguistics. An introduction, (București: Editura Didactică şi Pedagogică, 2005), 84.

${ }^{8}$ Sweetser, From etymology to pragmatic, 38.

${ }_{9}^{9}$ Ibarretxe-Antuñano, Iraide. "Polysemy and Metaphor in Perception Verbs: A Cross-Linguistic Study”, (PhD diss., University of Edinburgh, 1999), 113.

${ }^{10}$ Ibarretxe-Antuñano, Iraide. 'MIND-AS-BODY as a Cross-linguistic Conceptual Metaphor'. Miscelánea. A Journal of English and American studies 25 (2002): 114.

${ }^{11}$ Ibarretxe-Antuñano, Iraide, Vision Metaphors for the Intellect: Are they Really Cross-Linguistic? ATLANTIS. Journal of the Spanish Association of AngloAmerican Studies 30.1 (2008): 18.

${ }^{12}$ Brontë, Charlotte. Jane Eyre. (Great Britain: HarperCollinsPublishers, 2010), 17. 
${ }^{13}$ Brontë, Emily. Wuthering Heights. (Penguin Books, 1994), 261.

\section{REFERENCES}

Brontë, Charlotte. Jane Eyre. Great Britain: HarperCollinsPublishers, 2010. Brontë, Emily. Wuthering Heights. Penguin Books, 1994.

Ibarretxe-Antuñano, Iraide. "Polysemy and Metaphor in Perception Verbs: A Cross-Linguistic Study”, PhD diss., University of Edinburgh, 1999.

Ibarretxe-Antuñano, Iraide. 'MIND-AS-BODY as a Cross-linguistic Conceptual Metaphor'. Miscelánea. A Journal of English and American studies 25 (2002): 93-119.

Ibarretxe-Antuñano, Iraide, Vision Metaphors for the Intellect: Are they Really Cross-Linguistic? ATLANTIS. Journal of the Spanish Association of AngloAmerican Studies 30.1 (2008): 15-33.

Lakoff, George, and Mark Johnson. Metaphors We Live By. Chicago: University of Chicago Press, 1980.

Lakoff, George. Women, Fire and Dangerous Things. What Categories Reveal about the Mind. Chicago and London: Chicago University Press, 1987.

Neagu, Mariana. Cognitive Linguistics. An introduction, Bucureşti: Editura Didactică şi Pedagogică, 2005.

Rojo, Ana, and Javier Valenzuela. "Frame Semantics and Lexical Translation: the RISK frame and its translation." Babel Volume 44, No 2. (1998).

Sweetser, Eve. "Polysemy vs. Abstraction: Mutually Exclusive or Complementary". Proceedings of the Twelfth Annual Meeting of the Berkeley Linguistic Society. Berkeley, Ca.: Berkeley Linguistics Society, (1986): 528-538.

Sweetser, Eve. From etymology to pragmatics. Metaphorical and cultural aspects of semantic structure, Cambridge: Cambridge University Press, 1990.

Viberg, Äke. "The verbs of perception: a typological study" in Explanations for Language Universals edited by B. Comrie and O. Dahl (eds.). Berlin: Mouton de Gruyter, 1984: 123-162. 